$\mathrm{p}=0.46$ ), number of previous biological treatments ( $1.9 \pm 1.1 \mathrm{vs} 2 \pm 1.4 ; \mathrm{p}=0.84)$, VA ( $0.57 \pm 0.35$ vs $0.5 \pm 0.37 ; p=0.42)$, combined immunosuppressive therapy $(88 \%$ vs $75 \% ; p=0.37$ ), presence of cells in the anterior chamber (median, $1[0-1]$ vs $1[0.25-1.5] ; p=0.6)$, vitritis $(0[0-0]$ vs $0[0-1] ; p=0.7)$, macular thickening $(358.7 \pm 92.2$ vs $313.6 \pm 77.1 ; p=0.32)$.

There were no significant difference in the efficacy between TCZ and GLM (TABLE).

After a mean follow-up of $20.48 \pm 11.7$ months with TCZ and $24.25 \pm 17$ months with GLM the following side effects were observed: TCZ: viral conjunctivitis plus bullous impetigo $(n=1)$, severe thrombocytopenia and pneumonia. This last patient showed hemolytic anemia, thrombocytopenia and splenomegaly, for this reason treatment with TCZ was discontinued. With GLM cutaneous reaction was observed in 2 patients.

Table. Evolution of ocular parameters with TCZ and GLM

\begin{tabular}{|c|c|c|c|}
\hline & TCZ $(n=25)$ & GLM (n=8) & p \\
\hline \multicolumn{4}{|l|}{ BASELINE } \\
\hline VA & $0.57 \pm 0.35$ & $0.5 \pm 0.36$ & 0.43 \\
\hline Cells in the anterior chamber & $0.92 \pm 0.81$ & $2.79 \pm 4.82$ & 0.63 \\
\hline \begin{tabular}{|l|} 
Vitritis \\
\end{tabular} & $0,43 \pm 0,91$ & $0.33 \pm 0.5$ & 0.78 \\
\hline OCT & $358.69 \pm 92.17$ & $313.60 \pm 77.05$ & 0.31 \\
\hline \multicolumn{4}{|l|}{ 1STMONTH } \\
\hline VA & $0.59 \pm 0.33$ & $0.56 \pm 0.32$ & 0.75 \\
\hline Cells in the anteriorchamber & $0.26 \pm 0.52$ & $2.33 \pm 4.57$ & 0.083 \\
\hline \begin{tabular}{|l|} 
Vitritis \\
\end{tabular} & $0.31 \pm 0.71$ & $0 \pm 0$ & 0.32 \\
\hline OCT & $313.40 \pm 91.28$ & $292.50 \pm 111.42$ & 0.57 \\
\hline \multicolumn{4}{|l|}{$6^{\text {Th MONTH }}$} \\
\hline VA & $0.63 \pm 0.32$ & $0.62 \pm 0.33$ & 0.85 \\
\hline Cells in the anteriorchamber & $0,1 \pm 0,34$ & $0 \pm 3,28$ & 0.43 \\
\hline \begin{tabular}{|l|} 
Vitrtis \\
\end{tabular} & $0,07 \pm 0,33$ & $0,25 \pm 0,62$ & 0.62 \\
\hline$\overline{O C T}$ & $274,91 \pm 101,32$ & $261,37 \pm 75,15$ & 0.94 \\
\hline \multicolumn{4}{|l|}{$1^{\text {ST }}$ YEAR } \\
\hline VA & $0.63 \pm 0.34$ & $0.54 \pm 0.31$ & 0.35 \\
\hline Cells in the anterior chamber & $0 \pm 0.2$ & $0 \pm 0$ & 0.71 \\
\hline Vitritis & $0.058 \pm 0.23$ & $0 \pm 0$ & 0.81 \\
\hline OCT & $245.45 \pm 29.34$ & $255 \pm 120.8$ & 0.74 \\
\hline
\end{tabular}

Results are expressed as mean $\pm \mathrm{SD}$

Conclusions: TCZ and GLM seem to be equally effective and safe for refractory uveitis associated-JIA. The superiority of one or the other should be established with prospective randomized studies "Head to Head"

Disclosure of Interest: None declared

DOI: 10.1136/annrheumdis-2017-eular.3496

\section{OP0060 HEALTH BEHAVIOR IN ADOLESCENTS WITH JUVENILE IDIOPATHIC ARTHRITIS- RESULTS OF THE INCEPTION COHORT OF NEWLY DIAGNOSED PATIENTS (ICON)}

M. Listing ${ }^{1}$, I. Liedmann ${ }^{1}$, M. Niewerth ${ }^{1}$, J. Klotsche ${ }^{1}$, K. Mönkemöller ${ }^{2}$, I. Foeldvari ${ }^{3}$, J. Kümmerle-Deschner ${ }^{4}$, T. Hospach ${ }^{5}$, K. Minden ${ }^{1} .{ }^{1}$ Deutsches Rheuma-Forschungszentrum Berlin, Berlin; ${ }^{2}$ Klinik für Kinder- und Jugendmedizin, des Kinderkrankenhauses der Stadt Köln, Köln; ${ }^{3}$ Hamburger Zentrum für Kinder- und Jugendrheumatologie, Hamburg; ${ }^{4}$ Universitätsklinik für Kinder- und Jugendmedizin Tübingen, Tübingen; ${ }^{5}$ Zentrum für pädiatrische Rheumatologie, Klinikum Stuttgart, Stuttgart, Germany

Background: Knowledge concerning health behavior in adolescents with juvenile idiopathic arthritis (JIA) is essential for assessing their health risks. Although there is some evidence about a relationship between low socioeconomic status (SES) and health risk behavior in adulthood, it is less clear whether this association is also true for adolescents with JIA.

Objectives: To compare the health behavior between adolescents with JIA and healthy peers and to examine the association with sex and SES.

Methods: Data of adolescents (aged 13 to 17) with JIA and healthy peers enrolled in ICON were considered for this analysis. Health behavior was assessed via questionnaire within the first years of disease. SES- Score (low, moderate, high) was determined by using an established German multidimensional aggregated index and based on the parents' education level as well as household net income. Results: A total of 334 adolescents with JIA ( $61 \%$ female, mean age 15.1 (SD 1.1), mean disease duration 1.3 (SD 1.7)) and 181 healthy peers (57\% female, mean age 15.3 (SD 1.3)) were included. Adolescents with JIA were less physically active and reported less consumption of alcohol compared with healthy peers (see Table). In both groups, boys were more frequently physically active and spent more time in playing video games than girls. Whereas girls with and without JIA

\begin{tabular}{lccc}
\hline & $\begin{array}{c}\text { Adolescents with JIA } \\
(\mathrm{n}=334)\end{array}$ & $\begin{array}{c}\text { Healthy peers } \\
(\mathrm{n}=181)\end{array}$ & $\mathrm{p}$-value \\
\hline Watching TV $<1 \mathrm{~h} /$ day, $\mathrm{n}(\%)$ & $110(33 \%)$ & $68(38 \%)$ & 0.3 \\
Playing games and computer use $<1 \mathrm{~h} /$ day, $\mathrm{n}(\%)$ & $121(37 \%)$ & $61(34 \%)$ & 0.6 \\
Mobile phone use $<1 \mathrm{~h} /$ day, $\mathrm{n}(\%)$ & $159(48 \%)$ & $94(52 \%)$ & 0.4 \\
Physical activity $\geq$ once per week, $\mathrm{n}(\%)$ & $226(80 \%)$ & $169(94 \%)$ & $<0.001$ \\
No smoking, $\mathrm{n}(\%)$ & $313(94 \%)$ & $173(96 \%)$ & 0.3 \\
No consumption of alcohol, $\mathrm{n}(\%)$ & $168(52 \%)$ & $70(40 \%)$ & $<0.01$ \\
No consumption of illicit drugs in the last & & & \\
$\quad$ last 12 months, $\mathrm{n}(\%)$ & $301(96 \%)$ & $162(96 \%)$ & 0.9 \\
Ever sexual intercourse, $\mathrm{n}(\%)$ & $27(8 \%)$ & $13(7 \%)$ & 0.7 \\
\hline
\end{tabular}

used more often mobile phones than boys. No gender specific differences in both groups were found in consumption of illicit and legal drugs.

After stratification in groups according to the SES- Scores, socioeconomic differences were the same in adolescents with JIA and healthy peers. Teenagers with low social background $(n=200)$ spent significantly more time in consumption of TV, mobile phones and video games than those from families with high SES $(n=122)$. No significant relationship was found between parental SES and alcohol, nicotine and drug consumption by adolescents. The parental SES- Score was strongly associated with the education level of adolescents.

Conclusions: Adolescents with JIA have a similar health behavior as healthy peers, except for alcohol consumption and physical activity level. Gender and socioeconomic status are associated with health behavior of adolescents with and without JIA. Parental SES may affect adolescents' educational outcomes.

Acknowledgements: ICON is supported by a grant from the Federal Ministry of Education and Research (FKZ: 01ER0812).

Disclosure of Interest: M. Listing: None declared, I. Liedmann: None declared, M. Niewerth: None declared, J. Klotsche: None declared, K. Mönkemöller: None declared, I. Foeldvari: None declared, J. Kümmerle-Deschner: None declared, T. Hospach: None declared, K. Minden Speakers bureau: Pfizer, Roche, PharmAllergan

DOI: 10.1136/annrheumdis-2017-eular.4720

\section{OP0061 DIFFUSE ALVEOLAR HEMORRHAGE: A MULTICENTER STUDY IN 847 CHILDHOOD-ONSET SYSTEMIC LUPUS ERYTHEMATOSUS PATIENTS}

C.A. Silva ${ }^{1}$, G. Blay ${ }^{2}$, J.C. Rodrigues ${ }^{3}$, G.N. Leal ${ }^{2}$, J.C. Ferreira ${ }^{2}$, G. Novak $^{2}$, R.M.R. Pereira ${ }^{4}$, M.T. Terreri ${ }^{5}$, C.S. Magalhães ${ }^{6}$, B.C. Molinari ${ }^{2}$, A.P. Sakamoto ${ }^{5}$, N.E. Aikawa ${ }^{2,4}$, L.M.A. Campos ${ }^{2}$, T.A.P. Fernandes ${ }^{6}$, G. Clemente ${ }^{5}$, O.A.B. Peracchi ${ }^{5}$, V. Bugni ${ }^{5}$, R. Marini ${ }^{7}$, S.B. Sacchetti ${ }^{8}$ L.M. Carvalho ${ }^{9}$, M.M. Fraga ${ }^{10}$, T.C.M. Castro ${ }^{11}$, V.C. Ramos ${ }^{12}$, E. Bonfá ${ }^{2}$, C.A. Silva ${ }^{2,3}$ on behalf of Brazilian Childhood-onset Systemic Lupus Erythematosus Group. ${ }^{1}$ Pediatric Rheumatology Divisions, Brazilian Childhood-onset Systemic Lupus Erythematosus Group, São Paulo state; ${ }^{2}$ Pediatric Rheumatology Unit, Children's Institute, Hospital das Clinicas HCFMUSP, Faculdade de Medicina, Universidade de São Paulo; ${ }^{3}$ Pediatric Pulmonology Unit, Children's Institute, FMUSP; ${ }^{4}$ Division of Rheumatology, FMUSP; ${ }^{5}$ Pediatric Rheumatology Unit, Universidade Federal de São Paulo; ${ }^{6}$ São Paulo State University (UNESP), Faculdade de Medicina de Botucatu; ${ }^{7}$ São Paulo State University of Campinas (UNICAMP); ${ }^{8}$ Irmandade da Santa Casa de Misericórdia de São Paulo; ${ }^{9}$ Ribeirão Preto Medical School - University of São Paulo; ${ }^{10}$ Hospital Darcy Vargas; ${ }^{11}$ Hospital Menino Jesus; ${ }^{12}$ Pontifical Catholic University of Sorocaba, São Paulo, Brazil

Background: Data of diffuse alveolar hemorrhage (DAH) in childhood-onset systemic lupus erythematosus (CSLE) patients are limited due to the small representation of this complication in previous case series or the focus on the comparison to adult SLE, precluding an accurate analysis of associated factors and outcomes in patients with and without this severe complication.

Objectives: To evaluate prevalence, clinical manifestations, laboratory abnormalities and treatment in a multicenter cohort study including 847 cSLE patients with and without diffuse DAH, as well as concomitant parameters of severity.

Methods: DAH was defined as the presence of at least three respiratory symptoms or signs associated with diffuse interstitial/alveolar infiltrates on chest $x$-ray or high-resolution computer tomography and sudden drop in hemoglobin levels with no other source of bleeding. Holm-Bonferroni correction for multiple comparisons was performed adjusting the significance level $(p<0.0022)$.

Results: DAH was evidenced in 19/847 (2.2\%) CSLE patients. Cough/dyspnea/ tachycardia/hypoxemia occurred in all cSLE patients with DAH. Concomitant parameters of severity observed were: mechanical ventilation in $14 / 19(74 \%)$, hemoptysis $12 / 19(63 \%)$, macrophage activation syndrome 2/19 (10\%) and death 9/19 (47\%). Further analysis of CSLE patients at DAH diagnosis compared to 76 CSLE control patients without DAH with same disease duration [3 (1-151) vs. 4 (1151) months, $p=0.335]$, showed higher frequencies of constitutional involvement ( $74 \%$ vs. $10 \%, p<0.0001)$, serositis ( $63 \%$ vs. $6 \%, p<0.0001)$ and sepsis $(53 \%$ vs. $9 \%, p<0.0001$ ) in the DAH group. The median of disease activity score (SLEDAI$2 \mathrm{~K}$ ) was significantly higher in cSLE patients with DAH [18 $(5-40)$ vs. $6(0-44)$, $p<0.0001]$. The frequencies of thrombocytopenia ( $53 \%$ vs. $12 \%, p<0.0001$ ), intravenous methylprednisolone ( $95 \%$ vs. $16 \%, p<0.0001)$ and intravenous cyclophosphamide $(47 \%$ vs. $8 \%, p<0.0001)$ were also significantly higher in DAH patients. Conclusions: This is the largest study to evaluate DAH. This complication, although not a disease activity score descriptor, occurs in the context of significant moderate/severe cSLE flare. Importantly, we identified that this condition is associated with serious disease flare complicated by sepsis and with high mortality rate.

Acknowledgements: This study was supported by research grants from Conselho Nacional de Desenvolvimento Científico e Tecnológico (CNPq 301805/2013-0 to RMRP, 303752/2015-7 to MTT, 301479/2015-1 to CSM, 305068/2014-8 to EB and 303422/2015-7 to CAS), Federico Foundation (to EB, RMRP and CAS) and by Núcleo de Apoio à Pesquisa "Saúde da Criança e do Adolescente" da USP (NAP-CriAd) to CAS.

Disclosure of Interest: None declared

DOI: 10.1136/annrheumdis-2017-eular.4826 